\title{
Article \\ Assessing the Effect of Drivers' Gender on Their Intention to Use Fully Automated Vehicles
}

\author{
Sergio A. Useche ${ }^{1,2, *(\mathbb{D}}$, María Peñaranda-Ortega ${ }^{3}$, Adela Gonzalez-Marin ${ }^{4}$ and Francisco J. Llamazares ${ }^{5}$ \\ 1 Research Institute on Traffic and Road Safety (INTRAS), University of Valencia, 46022 Valencia, Spain \\ 2 Spanish Foundation for Road Safety (FESVIAL), 28004 Madrid, Spain \\ 3 Department of Basic Psychology and Methodology, University of Murcia, 30100 Murcia, Spain; mariap@um.es \\ 4 Economic and Legal Sciences, University Center of Defense, 30720 Murcia, Spain; adelaglez@cop.es \\ 5 Department of Technology, ESIC University, Pozuelo de Alarcón, 28223 Madrid, Spain; \\ javier.1lamazares@esic.university \\ * Correspondence: sergio.useche@uv.es
}

Citation: Useche, S.A.; PeñarandaOrtega, M.; Gonzalez-Marin, A.; Llamazares, F.J. Assessing the Effect of Drivers' Gender on Their Intention to Use Fully Automated Vehicles. Appl. Sci. 2022, 12, 103. https:// doi.org/10.3390/app12010103

Academic Editors: Guoming Liu and Xiangming $\mathrm{Hu}$

Received: 10 November 2021

Accepted: 17 December 2021

Published: 23 December 2021

Publisher's Note: MDPI stays neutral with regard to jurisdictional claims in published maps and institutional affiliations.

Copyright: (C) 2021 by the authors. Licensee MDPI, Basel, Switzerland. This article is an open access article distributed under the terms and conditions of the Creative Commons Attribution (CC BY) license (https:// creativecommons.org/licenses/by/ $4.0 /)$.

\begin{abstract}
Although fully automated vehicles (SAE level 5) are expected to acquire a major relevance for transportation dynamics by the next few years, the number of studies addressing their perceived benefits from the perspective of human factors remains substantially limited. This study aimed, firstly, to assess the relationships among drivers' demographic factors, their assessment of five key features of automated vehicles (i.e., increased connectivity, reduced driving demands, fuel and trip-related efficiency, and safety improvements), and their intention to use them, and secondly, to test the predictive role of the feature' valuations over usage intention, focusing on gender as a key differentiating factor. For this cross-sectional research, the data gathered from a sample of 856 licensed drivers $(49.4 \%$ females, $50.6 \%$ males; $M=40.05$ years), responding to an electronic survey, was analyzed. Demographic, driving-related data, and attitudinal factors were comparatively analyzed through robust tests and a bias-corrected Multi-Group Structural Equation Modeling (MGSEM) approach. Findings from this work suggest that drivers' assessment of these AV features keep a significant set of multivariate relationships to their usage intention in the future. Additionally, and even though there are some few structural similarities, drivers' intention to use an AV can be differentially explained according to their gender. So far, this research constitutes a first approximation to the intention of using AVs from a MGSEM gender-based approach, being these results of potential interest for researchers and practitioners from different fields, including automotive design, transport planning and road safety.
\end{abstract}

Keywords: vehicle automation; features; fully automated cars; Multi-Group Structural Equation Modeling (MGSEM); gender; intention; drivers; roadway technologies

\section{Introduction}

\subsection{Automated Vehicles: What Could Drive People to "Make the Shift"?}

Nowadays, it is widely known that vehicle-related technologies constitute a core focus to increase safety, efficiency and sustainability of mobility. Accordingly, several technological improvements aimed at supporting a safer and easier driving experience have been developed during the last few decades (e.g., ADAS and other active/passive safety improvements), bringing the automotive market closer and closer to full automation [1,2], thus progressively increasing the SAE level of the vehicles available on the market, looking ahead to the next decade in which, for the case of European countries, about $30 \%$ of them are expected to be fully automated (SAE level 5) vehicles [3].

Further, most of the prospective sources on the matter agree on the fact that (just like in any other market) users' perceptions and attitudes play a crucial role for the future of automated vehicles (AVs) and their related transportation dynamics, even though the available empirical information in this regard remains considerably limited $[4,5]$. 
However, and as a consequence of different technological, safety and mass communicationrelated constraints, some studies have argued that the intention to shift to fully automated vehicles could decrease if potential users do not attribute enough value to their different features, especially those related to safety, efficiency and stability [6]. An example of it is the considerable number of non-specialized sources often under or overstressing the actual capabilities of automated vehicles that, far from improving their market-transforming possibilities, can negatively influence both potential consumers' perceptions, same as the willingness of policymakers and transport planners to further invest on adapting road infrastructures as a way to enhance a safer, more sustainable and cost-effective mobility [1,4].

Among all the potential improvements that automated vehicles may represent for their potential users (yet drivers of "conventional" vehicles), there are some features that might be critical for influencing the intention to get involved in this new trend of transport dynamics. For instance, literature emphasizes key aspects such as information flows, ease of driving, energy efficiency, travel swiftness, and perceived safety as essential user-related perceptions to consider with the aim of fostering a more holistic and participatory transition towards automated driving [1,5,6]. Concretely, five of them were addressed in this study.

\subsection{Greater Connectivity: Networking Mobility}

Among all the social and mobility needs that are expected to be, at least partly, fulfilled through technological developments, recent studies have highlighted mobility networking as one of the core features to be offered by automated vehicles [7]. Instead of operating in a standalone mode, automated vehicles (whose functional basis largely lies on connectivity) are expected to compose cooperative networks useful for different tasks such as traffic control, flow and density monitoring, alerts on critical events and dynamic (real-time) accident prevention [8]. In other words, and apart from maximizing the capacity of urban roads to a substantial extent [9], automated cars are expected to improve "connected mobility" through different resources, including collaborative driving systems (CDS) and vehicle-to-vehicle communication (V2V) systems, thus improving the information available both for our car and for the others' vehicles to make accurately safe decisions [10,11].

Notwithstanding, and although the forecasts about safety, efficiency and technical improvements that having a "more connected" mobility through data sharing would entail, some studies have questioned the growing concerns of drivers in relation to key issues such as data privacy, network stability and reliability, and the possibility that their vehicles (or the networks to which they are connected) could be "hacked" by third parties and, consequently, their privacy and security would get threatened [1,12-14]. Precisely, a recent systematic review found that the behavioral intention to shift to an automated car can be substantially affected by technological fears which are becoming relatively common in current times [15].

\subsection{Reduction of Driving Demands}

Traditionally, one of the biggest concerns for road safety and vehicle design-related stakeholders (including researchers, designers and practitioners) has been the excessive amount of both physical and psychological demands that the task of driving implies $[2,16]$, especially in long-haul contexts, such as the case of professional driving $[17,18]$. This critical issue has been linked to different negative outcomes such as fatigue, stress and physical strain, that at the same time remain as reliable predictors of traffic crashes [19-21]. In fact, recent empirical studies have argued about the problematic role of recurrent driving demands also outside the field of professional driving. For instance, factors as common as time pressure may lead drivers to make unsafe decisions and to perform risky driving behaviors, increasing their likelihood to suffer crashes [16,22,23].

Precisely, one of the key benefits of vehicle automation is the progressive reduction of driving demands. For instance, both observational and self-report-based studies have already documented how SAE 2 level-incorporated ADAS (Advanced Driving Assistance 
Systems) reduce the number and degree of many (often simultaneous) demands to which drivers are subjected during their everyday trips [14,24].

However, it is worth mentioning that results in these aforementioned regards remain considerably inconsistent, whereas other researchers have argued that not all the potential users of automated vehicles would, actually, have a very positive valuation of the fact that a machine might take decisions and execute driving tasks on behalf of them, especially in cases such as: (i) they have a high preference for driving themselves, (ii) they consider that their driving skills can be better than anyone else's, often also over any machine, (iii) they either enjoy the experience of assuming sensations related to risk and speed, (iv) they can be afraid of losing their jobs or experiencing unexpected changes as a consequence of vehicle automation, and/or (v) they simply prefer "staying in control" of their cars, especially at safety-critical moments and complex driving scenarios [25-27].

\subsection{Fuel/Energy Consumption Saving}

One of the most commonly featured benefits of vehicle automation is vehicle energy efficiency [28], explaining an improved potential to transform energy-related dynamics in transport, thus increasing their contribution to both environmental sustainability (including greenhouse emissions) and economy [29,30]. In other words, it is expected a widespread adoption of automated cars might reasonably reduce air pollution and benefit many stakeholders, including drivers, passengers and other road users, especially when involved in large-use transport spheres and services, such as taxis and private hire cars (PHCs) [31].

Notwithstanding, recent studies highlight that, even though the projections are really promising in environmental terms, there are still many uncertainties prevailing around the actual operation of fully (SAE level 5) automated vehicles, as this basically remains a hypothesized technology [31,32], whose specific features should substantially vary during the next few years, also in consideration of different factors and dynamics that can be transformed (e.g., the price of different forms of energy, the ruling ones, the new technologies that could be discovered or massified and the storage capacity of batteries and their efficiency, in the case of electric cars) in the term of the next few years [33-35].

At the (potential) user level, however, advances in energy terms and their subsequent monetary savings are usually a relevant feature for decision-making, as has been evidenced in previous studies related to vehicle automation [28,36,37]. Indeed, sustainability-related settings are nowadays considered as a critical part of both the consolidation of automated (and clean) driving as a transportation pattern, and the consumer preferences of today's drivers, given the high level of social discussion on the subject and awareness of the issue that exists in most industrialized countries [37-39].

\subsection{Travel Efficiency}

Another key feature that should be addressed in relation to vehicle automation is their overall hypothesized substantial contribution to reduce costs and travel times [25,36]. Especially under conditions of high demand, automated vehicles and connected transport technologies are expected to help substantially reduce the average number of minutes a driver or passenger spends on each of their trips [40,41]. In a recent study, Sonnletiner, Friedrick and Richter determined that factors such as the improvement of current algorithms through artificial intelligence developments and machine learning, and the increasing number of units (connected cars) in urban traffic networks, despite experiencing some difficulties in their early implementation phases, could significantly optimize the trips and the time used for them in a few years [42].

Nevertheless, and regardless of objective estimations, the latest stated preference studies in these regards have shown how people's perceptions (that are theorized to exert an effect on demand rates) remain relatively skeptical in regard to the actual extent to which, in a near future, highly and fully automated vehicles (i.e., SAE levels 4 and 5) could, indeed, improve urban dynamics related to travel time and trip efficiency [43]. 


\subsection{Improved Safety}

Finally, the role of safety in vehicle automation must be addressed. Since a couple decades ago, different theoretical and empirical sources have argued that human knowledge and ability, even provided with greater autonomy, decision-making capacity and discernment, they are considerably lower when compared with most of the technologies commonly used in the field of vehicle automation $[9,11]$. Therefore, it could be expected that, in a relatively controlled environment (e.g., the so-called smart cities), the diversification of automated cars would help to reduce the number of errors, traffic violations and their subsequent accidents, injuries and deaths, in addition to all the subsequent costs that the aforementioned issues commonly involve [41].

At the user level, it is nowadays virtually impossible to provide rigorously suitable estimations on to what extent road safety will become benefited from the implementation and widespreading of automated vehicles, especially in absence of estimations about the extent to which drivers' behavior will remain as a core crash predictor $[6,15]$. However, some initial studies have determined that safety-related perceptions of nowadays' drivers might influence their intention to shift towards higher SAE level vehicles, but also that demographic differences of potential users (especially as for gender) might contribute to identify differences in the development of attitudes, perceptions and intentions towards automated cars and their driving assistance features $[1,6,43]$.

\subsection{Study Aims and Hypotheses}

Bearing in mind the aforementioned considerations and insights provided by previous literature, the two aims of this study were: first, to assess the relationships among drivers' demographic factors, their valuation of five key features of automated vehicles and the intention to use a fully automated AV in the future. In this regard, it was hypothesized that drivers' assessment of these features - that fully automated cars are expected to have-might be significantly related to their self-reported intention to switch to AVs.

Secondly, this study also aimed at testing the predictive role of the assessment given to these five features on drivers' intention to use automated cars, focusing on gender as a potentially differentiating factor. As for this second study aim, it was hypothesized that AV feature-based assessments would have a significant (but differential) effect over usage intention, i.e., there will exist structural differences in the explanation of the intention to use an automated vehicle depending on whether there is a male or a female driver.

\section{Methods}

\subsection{Design and Study Setting}

With the aim of providing a methodological overview to the readers, the steps of this cross-sectional study, successively described in the different subsections of the methods, are graphically synthesized in Figure 1.

Given the current COVID-19-related social distancing protocols, this cross-sectional research was performed through an electronic survey written in Spanish, distributed to an approximate number of 1550 individuals included in a pre-existing mailing list shared among universities and research centers during the first half of the year 2021. Potential participants included in the mailing list (whose basic features are overall similar to the general Spanish population, at least in terms of gender and age), were recruited through a convenience sampling method, receiving a personal invitation to partake in this study, stating its objective, participation dynamics and ethical considerations surrounding it.

The only two inclusion criteria were to be a currently licensed non-professional driver (regardless of the type of vehicle) residing in Spain, and to read and accept the conditions included in the Informed Consent form before starting to respond the questionnaire, which was mandatory. Additionally, it is worth saying that participants were briefly contextualized in SAE levels prior to responding the questionnaire, with the aim to differentiate the concepts of "partially-to-high automated vehicle" (SAE levels 2 to 4), and "fully automated vehicle" (SAE level 5). 


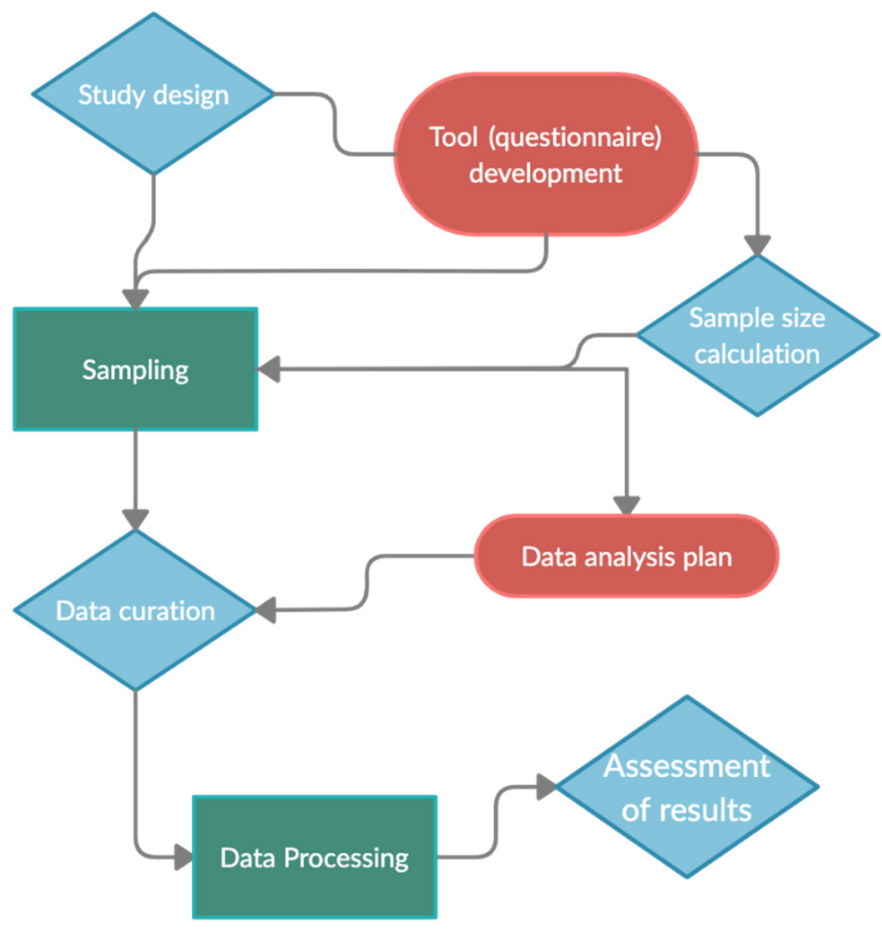

Figure 1. Data Flow Chart (DFC) describing the methodological steps of the study.

Regarding other sample-related issues, the response rate was about $56 \%$ of the invited partakers; no economical rewards or stimulus were offered to participants. In order to achieve an acceptable degree of representativeness: (i) we assumed the full Spanish census of drivers (about 27 million drivers for the year 2020) [44] as population size, and (ii) although population representativeness can be only partially assumed on the basis of a non-probabilistic sampling method, an a priori calculation of the minimum sample size was carried out using the following formula:

$$
\left(S=z^{2} \sigma / e^{2}\right)
$$

where $S$ represents the sample size; $z$ the standardized value for different levels of confidence, e.g., $z=1.96_{(95 \%)}$, or $2.58_{(99 \%)}, \sigma$ represents the standard deviation (commonly set as 0.50$)$, and $e$ represents the maximum error allowed, with $\alpha=0 \tilde{n} 0.05_{(5 \%)}$. The resulting number suggested a minimum of about 690 subjects (better if proportionally distributed by sex and age), assuming a maximum margin of error of $5 \%(\alpha=0.05)$ and a beta $(\beta)$ of 0.20 , which allows for an $80 \%$ power. It is worth saying that, although this implies the need of retrieving more cases, it lessens the margin of error of the study.

The average time required to partake in the research (i.e., responding to the electronic survey) was about $8 \mathrm{~min}$. In order to avoid potentially biased responses, before starting the survey, it was emphasized that the data would be exclusively used for statistical research purposes and their participation was anonymous.

\subsection{Study Sample}

This study analyzed the data obtained from a sample of $n=856$ licensed drivers aged between 18 and 65 , with a mean of $M=40.05(S D=11.47)$ years. Participants were residents of all the 17 Autonomous Communities (Regions) of Spain, with a sample proportion between $4-9 \%$ per region. From the study sample, $49.4 \%$ of the drivers were females and $50.6 \%$ were males. Table 1 presents detailed demographic characteristics of the study participants. 
Table 1. Study partakers' sociodemographic data and basic driving features.

\begin{tabular}{|c|c|c|c|c|}
\hline Feature & Category & Frequency & Percentage & Population Census Data $^{a}$ \\
\hline \multirow{2}{*}{ Gender } & Female & 423 & $49.4 \%$ & $50.9 \%$ \\
\hline & Male & 433 & $50.6 \%$ & $49.1 \%$ \\
\hline \multirow{5}{*}{ Age Group } & $<25$ & 92 & $10.7 \%$ & $8.2 \% \mathrm{~b}$ \\
\hline & $25-34$ & 197 & $23 \%$ & $13.0 \%$ \\
\hline & $35-44$ & 253 & $29.5 \%$ & $17.4 \%$ \\
\hline & $45-54$ & 223 & $26 \%$ & $18.7 \%$ \\
\hline & $>54$ & 91 & $10.6 \%$ & $42.7 \%$ \\
\hline \multirow{4}{*}{ Educational level } & Primary school & 63 & $7.4 \%$ & \\
\hline & Secondary-high school & 376 & $43.9 \%$ & \\
\hline & Technical education & 133 & $15.5 \%$ & \\
\hline & University & 284 & $33.2 \%$ & \\
\hline \multirow{3}{*}{ Years since firstly licensed } & Less than 5 years & 102 & $11.9 \%$ & \\
\hline & 5 to 10 years & 138 & $16.1 \%$ & \\
\hline & More than 10 years & 616 & $72 \%$ & \\
\hline \multirow{4}{*}{ Type of vehicle (most driven) } & Private car & 801 & $93.5 \%$ & \\
\hline & Motorcycle & 32 & $3.7 \%$ & \\
\hline & Van/Light truck & 14 & $1.6 \%$ & \\
\hline & $\begin{array}{l}\text { Other (moped, electric } \\
\text { two-seater) }\end{array}$ & 9 & $1.2 \%$ & \\
\hline \multirow{4}{*}{ Driving frequency (weekly basis) } & Daily & 376 & $44 \%$ & \\
\hline & 4-6 days a week & 239 & $27.9 \%$ & \\
\hline & 2-3 days a week & 141 & $16.6 \%$ & \\
\hline & 1 day a week or less & 100 & $11.7 \%$ & \\
\hline
\end{tabular}

Notes for the Table: ${ }^{\text {a }}$ Population-based data [44] was included to compare sample distribution in terms of gender and age group; ${ }^{\mathrm{b}}$ age group percentages are based on the population census over 18 , to make it comparable with driving population.

\subsection{Description of the Questionnaire}

The research questionnaire was composed of four main sections:

The first section inquired about demographic data, including gender (male/female/other; "other" was never chosen as a response, so that the variable was dichotomized), educational level, city of residence, income level and driving-related information (years since firstly licensed, type of vehicle most commonly driven, driving frequency).

The second part of the survey comprised a Likert-based questionnaire consisting of 20 questions, using a 5-point (1-5) scale, i.e., from 1 (not at all $\rightarrow$ no relevance/value/improvement perceived at all) to 5 (too much $\rightarrow$ much relevance/value/improvement perceived). Drivers were asked about their assessment of five different key characteristics of fully automated vehicles, namely: greater connectivity (4 items; $\alpha=0.726$ ), reduced driving demands (4 items; $\alpha=0.705$ ), energy efficiency (4 items; $\alpha=0.769$ ), travel efficiency (4 items; $\alpha=0.762$ ), and improved safety ( 4 items; $\alpha=0.801$ ). The valuation of these features was based on a four-item subscale for each feature, addressing: (a) perceived relevance; (b) value attributed; (c) the degree to which it may improve driving experience, and (d) the actual viability or likelihood of the feature.

The third part of the survey comprised a 5-item $(\alpha=0.840)$ attitude questionnaire aimed at assessing drivers' intention to use an automated vehicle (example item: If during the next years I will have enough budget, I plan to buy an AV). The scale used a (1-5) scale, being 1 (totally disagree) and 5 (totally agree) [6].

Finally, the fourth part of the survey was aimed to assess drivers' degree of interaction with Information and Communication Technologies (ICTs; to be used as a control variable) in a scale ranging between 1 (very scarce interaction) and 5 (very high interaction). The item used for this purpose was: "Please tell us your degree of usual interaction with smartphones, computers and/or other devices which are normally connected to the Internet". 


\subsection{Data Processing}

After performing basis statistical procedures, i.e., descriptive statistics, bivariate Spearman's $r_{s}$ or rho correlations and Brown-Forsythe's mean comparisons (robust tests, as basic normality and homoscedasticity-related assumptions were not met), a gender-based Multi-Group Structural Equation Model (MGSEM) was built up. For this purpose, there were used Bootstrap-based robust maximum likelihood estimations (i.e., 10,000 bootstrap samples and $95 \%$ confidence intervals), in order to handle non-normality issues, as most of the study variables did not meet the basic assumption of univariate normality, and multivariate normality was not met either, as usually happens in self-report-based studies [45]. The model fit was evaluated by using Chi-square $\left(\chi^{2}\right)$, Normed Fit Index (NFI), Incremental Fit Index (IFI), Comparative Fit Index (CFI), and Root Mean Square Error of Approximation (RMSEA) [18].

As for the punctual features of the model used to test the hypothesized structural relationships among measured variables, the multivariate relationships between female and male drivers' demographic/psychosocial factors and their intention to use an AV, it was composed of the six exogenous variables and one endogenous factor that are shown in Section 3.3. This is statistically more accurate than separately testing genders as separate populations since it considers the full sample parameters for fitting the models. The direct effects of the model, their confidence intervals (at the level 95\%) and significance levels were calculated following the bootstrap method, specifically through a Monte Carlo (parametric) procedure, favoring that, e.g., the results of the estimates may be bias-corrected, do not present problems of normality, type I errors (false positives) in regression paths can be avoided, and constitutes a reasonable alternative to other estimation methods such as Satorra-Bentler or Weighted Least Square Mean and Variance adjusted (WLSMV). For this study, SEM modeling tasks were performed with SPSS AMOS software (Version 26.0; IBM Corp., Armonk, NY, USA).

Estimators were calculated controlling for income level, degree of interaction with ICTs and driving experience. According to the specialized literature $[18,46]$, it is commonly accepted, as rules of thumb, that a set of CFI/NFI/IFI coefficients greater than 0.900 and a Root Mean Square Error of Approximation lower than 0.080 (better if $<0.060$; [18]), plus the coherence of the model data with its theoretical assumptions, constitute insights of an acceptable model fit to the data. When possible, the model's fit was improved taking into account the largest and more theoretically parsimonious modification indexes.

\section{Results}

\subsection{Descriptive Data}

Table 2 shows the mean values and non/parametric bivariate correlations of the variables measured in the study, divided in three blocks: participants' demographic data, their assessment of five automated vehicle features, and their intention to use them.

Spearman's $(r h o)$ correlation coefficients can be interpreted similarly to Pearson's $(r)$ coefficients, ranging between -1 (very strong negative association) and 1 very strong positive association, where 0 implies there is no relation between two variables. Overall, demographic variables, and especially age, have shown interesting associations with the valuation of two of these features. Concretely, age has been found significantly (and negatively) associated with the valuation of AVs' greater connectivity and reduced driving demands. In other words, the higher the drivers' age, the lesser is their valuation of these two AV features. Further, it draws attention to how drivers with a greater degree of interaction to Information and Communication Technologies (ICTs) tend to value to a greater extent travel efficiency and increased safety features, but also to self-report a greater intention to shift to an automated vehicle, also raising the need of including age and interaction with ITCs among the control variables to perform inferential models on the intention to use AVs (see Section 3.3). 
Table 2. Basic descriptive data and bivariate (Spearman's rho) correlations between study variables.

\begin{tabular}{|c|c|c|c|c|c|c|c|c|c|c|c|}
\hline & Variable & Mean $^{a}$ & $\mathrm{SD}^{\mathrm{b}}$ & 1 & 2 & 3 & 4 & 5 & 6 & 7 & 8 \\
\hline \multicolumn{12}{|c|}{ Demographic data } \\
\hline 1 & Age & 40.05 & 11.47 & $-^{c}$ & & & & & & & \\
\hline 2 & Educational Level & $-c$ & - & $-0.117^{* *}$ & - & & & & & & \\
\hline 3 & Interaction with ICTs & 2.82 & 0.98 & $-0.214^{* *}$ & $0.191 * *$ & - & & & & & \\
\hline \multicolumn{12}{|c|}{ Assessment of five automated car features } \\
\hline 4 & Greater connectivity & 3.25 & 1.98 & $-0.109^{* *}$ & 0.060 & 0.003 & - & & & & \\
\hline 5 & Reduced driving demands & 1.90 & 1.67 & $-0.124^{* *}$ & 0.025 & 0.051 & -0.025 & - & & & \\
\hline 6 & $\begin{array}{c}\text { Fuel/energy } \\
\text { consumption saving }\end{array}$ & 3.42 & 1.01 & 0.036 & 0.044 & 0.067 & $-0.161^{* *}$ & $-\underset{* *}{-0.105}$ & - & & \\
\hline 7 & Travel efficiency & 3.29 & 0.94 & 0.021 & 0.026 & $0.114 * *$ & $-0.207^{* *}$ & $\underset{* *}{-0.148}$ & $0.457^{* *}$ & - & \\
\hline 8 & Increased safety & 2.63 & 0.62 & 0.043 & $0.071 *$ & $0.075^{*}$ & $-0.285^{* *}$ & $-\underset{* *}{0.203}$ & 0.391 ** & $0.506^{* *}$ & \\
\hline \multicolumn{12}{|c|}{ Intention to use an automated car } \\
\hline
\end{tabular}

Notes for the Table: ${ }^{a}$ Average value for the full sample; ${ }^{b} \mathrm{SD}=$ standard deviation; ${ }^{\mathrm{c}}$ value cannot be computed (applies to purely ordinal variables or the correlation of a variable with itself, where 1.0 is an invariant value); * correlation is significant at the $p<0.050$ level (2-tailed); ${ }^{* *}$ correlation is significant at the $p<0.010$ level (2-tailed).

As for the bivariate relationships between the intention to use AVs and the five features covered by this study, it was found that higher scores on the assessment of a greater connectivity and reduced driving demands are negatively correlated with the valuation of fuel saving, travel efficiency and safety features. On the other hand, the bivariate correlations between increased safety, trip efficiency and lower energy consumption assessments remain positive among them, same as with the intention to use AVs. In other words, it seems that the improvements developed in these three terms might be (among the five) those that are, indeed, potentially associated with a greater intention to shift to an automated vehicle in the near future.

\subsection{Gender-Based Differences}

After assessing bivariate correlations between these three groups of variables, descriptive gender differences were explored. Given that the assumption of normality was not met in the case of most variables used in the study, especially because Likert questionnaires have an ordinal nature, and variances were rather heteroscedastic, robust (Brown- Forsythe's F) tests were used for this purpose. Unlike traditional ANOVA tests, this technique uses a different denominator for the " $F$ " equation, adjusting the mean square through the observed variances of each group, instead of dividing by the mean square of the error. The results of mean comparison tests are fully available in Table 3, being readable and interpretable in the same way as One-way Analysis of Variance tests.

Overall, significant differences could be established between three out of the five AV features addressed in the study, namely: Fuel/energy consumption saving, Travel efficiency and Increased safety, where valuations were always higher among male drivers. On the other hand, females: (i) self-report a greater level of interaction with ICTs than males and (ii) tend to value to a greater extent the AVs' greater connectivity and driving demands reduction, but these differences do not reach the cut-off points needed for assuming significance at a $95 \%$ level of confidence.

\subsection{Structural Analyses}

Based on the aforementioned theoretical assumptions of the study, the effect of gender over the extent to which male and female drivers intend to use an AV was examined through a MGSEM (Multi-Group Structural Equation Modeling) approach, that differs from using gender as a dummy category within a structural model encompassing other predictive variables, whose effects can be hypothesized to differ in nature according to drivers' gender. Instead, it allows differentially assessing the effect of the exogenous factors on the dependent variable for each group, making it possible to compare the "mechanisms" by which these relations can be explained for the case of each gender. 
Table 3. Descriptive statistics and mean comparisons by driver's gender.

\begin{tabular}{|c|c|c|c|c|c|c|c|}
\hline \multirow{2}{*}{ Variable } & \multirow{2}{*}{ Group } & \multicolumn{2}{|c|}{ Descriptives } & \multicolumn{4}{|c|}{ Brown-Forsythe Test } \\
\hline & & Mean & SD & Statistic $^{a}$ & $\mathrm{df}^{\mathrm{b}}$ & df $2^{c}$ & Sig. \\
\hline Interaction with ITCs & $\begin{array}{c}\text { Males } \\
\text { Females }\end{array}$ & $\begin{array}{l}2.75 \\
2.90\end{array}$ & $\begin{array}{l}0.94 \\
1.01\end{array}$ & 4.921 & 1 & 847.620 & $<0.001 * * *$ \\
\hline Greater connectivity & $\begin{array}{c}\text { Males } \\
\text { Females }\end{array}$ & $\begin{array}{l}3.11 \\
3.39\end{array}$ & $\begin{array}{l}2.00 \\
1.96\end{array}$ & 3.259 & 1 & 653.656 & $0.072^{\mathrm{N} / \mathrm{S}}$ \\
\hline Reduced driving demands & $\begin{array}{c}\text { Males } \\
\text { Females }\end{array}$ & $\begin{array}{l}1.81 \\
1.98\end{array}$ & $\begin{array}{l}1.61 \\
1.73\end{array}$ & 1.705 & 1 & 653.961 & $0.192^{\mathrm{N} / \mathrm{S}}$ \\
\hline Fuel/energy consumption saving & $\begin{array}{c}\text { Males } \\
\text { Females }\end{array}$ & $\begin{array}{l}3.52 \\
3.30 \\
\end{array}$ & $\begin{array}{l}1.02 \\
0.98 \\
\end{array}$ & 9.785 & 1 & 853.793 & $0.008^{* *}$ \\
\hline Travel efficiency & $\begin{array}{c}\text { Males } \\
\text { Females }\end{array}$ & $\begin{array}{l}3.44 \\
3.13\end{array}$ & $\begin{array}{l}0.95 \\
0.91 \\
\end{array}$ & 23.882 & 1 & 853.707 & $<0.001 * * *$ \\
\hline Increased safety & $\begin{array}{c}\text { Males } \\
\text { Females }\end{array}$ & $\begin{array}{l}2.73 \\
2.52\end{array}$ & $\begin{array}{l}0.70 \\
0.64\end{array}$ & 21.911 & 1 & 850.655 & $<0.001 * * *$ \\
\hline Intention to use & $\begin{array}{c}\text { Males } \\
\text { Females }\end{array}$ & $\begin{array}{l}2.86 \\
2.76\end{array}$ & $\begin{array}{l}0.60 \\
0.61\end{array}$ & 6.413 & 1 & 852.986 & $0.035^{*}$ \\
\hline
\end{tabular}

Notes for the Table: ${ }^{\mathrm{a}}$ Asymptotically $\mathrm{F}$ distributed; ${ }^{\mathrm{b}} \mathrm{df} 1=\mathrm{B}-\mathrm{F}$ test degrees of freedom $1{ }^{\mathrm{c}} \mathrm{df} 2=\mathrm{B}-\mathrm{F}$ test degrees of freedom 2 ; ${ }^{*}$ significant at the $p<0.050$ level (2-tailed); ** significant at the $p<0.010$ level (2-tailed); ${ }^{* * *}$ significant at the $p<0.001$ level (2-tailed); ${ }^{\mathrm{N} / \mathrm{S}}$ non-significant difference.

In this sense, data were split into two gender-based groups (i.e., reference categories): a group of $423(49.4 \%)$ female, and a group of $433(50.6 \%)$ male drivers, both of them with acceptable sample size and proportionality for a comparative examination. Utilizing multi-group (MGSEM) analysis, the hypothesized structural model was adjusted to control for demographic and driving-related differences, and to fit the data according to gender, at the same time considering the parameters of the full sample.

The resulting Structural Equation Model, simultaneously fitted for both gender groups $\left(x^{2}{ }_{(13)}=73.220, p<0.001 ; \mathrm{NFI}=0.917 ; \mathrm{CFI}=0.926\right.$; IFI $=0.930 ; \mathrm{RMSEA}=0.077$, CI $90 \%=0.061-0.095)$, is presented through two merged graphical models in Figure 2. Qualitatively, the magnitude and significance levels of paths from exogenous variables to self-reported rates show differential trends between male and female drivers.

Table 4. Multi-group SEM model to predict drivers' intention to use automated vehicles.

\begin{tabular}{|c|c|c|c|c|c|c|}
\hline \multicolumn{7}{|c|}{ Group A: Male Drivers } \\
\hline \multicolumn{3}{|r|}{ Path } & \multirow{2}{*}{$\frac{\text { S.P.C. }^{\mathrm{a}}}{0.086}$} & \multirow{2}{*}{$\frac{\text { S.E. }^{\mathbf{b}}}{0.04}$} & \multirow{2}{*}{$\frac{\text { C.R. }^{\mathrm{c}}}{2.102}$} & \multirow{2}{*}{$\frac{p^{\mathrm{d}}}{0.036^{*}}$} \\
\hline Intention & $\leftarrow$ & Interaction with ICTs & & & & \\
\hline Intention & $\leftarrow$ & Greater connectivity & -0.106 & 0.096 & -2.191 & $0.028 *$ \\
\hline Intention & $\leftarrow$ & Reduction of driving demands & 0.058 & 0.118 & 1.201 & $0.230^{\mathrm{N} / \mathrm{S}}$ \\
\hline Intention & $\leftarrow$ & Fuel/energy consumption saving & 0.104 & 0.045 & 2.229 & 0.026 * \\
\hline Intention & $\leftarrow$ & Travel efficiency & 0.231 & 0.013 & 4.751 & $<0.001^{* * *}$ \\
\hline Intention & $\leftarrow$ & Increased safety & 0.301 & 0.05 & 6.128 & $<0.001^{* * *}$ \\
\hline \multicolumn{7}{|c|}{ Group B: Female Drivers } \\
\hline \multicolumn{3}{|r|}{ Path } & S.P.C. & S.E. & C.R. & $p$ \\
\hline Intention & $\leftarrow$ & Interaction with ICTs & 0.017 & 0.045 & 0.417 & $0.677^{\mathrm{N} / \mathrm{S}}$ \\
\hline Intention & $\leftarrow$ & Greater connectivity & 0.048 & 0.099 & 1.02 & $0.308^{\mathrm{N} / \mathrm{S}}$ \\
\hline Intention & $\leftarrow$ & Reduction of driving demands & 0.157 & 0.112 & 3.315 & $<0.001^{* * *}$ \\
\hline Intention & $\leftarrow$ & Fuel/energy consumption saving & 0.056 & 0.049 & 1.173 & $0.241^{\mathrm{N} / \mathrm{S}}$ \\
\hline Intention & $\leftarrow$ & Travel efficiency & 0.166 & 0.014 & 3.241 & $0.002 * *$ \\
\hline Intention & $\leftarrow$ & Increased safety & 0.397 & 0.056 & 7.941 & $<0.001 * * *$ \\
\hline
\end{tabular}

Notes for the Table: ${ }^{\text {a }}$ S.P.C. $=$ Standardized path coefficient; ${ }^{\mathrm{b}}$ S.E. $=$ standard error; ${ }^{\mathrm{c}}$ C.R. $=$ critical ratio; ${ }^{\mathrm{d}}$ bias corrected $p$-value; ${ }^{*}=$ path is significant at the level $p<0.050 ;{ }^{* *}=$ path is significant at the level $p<0.010 ;{ }^{* * *}=$ path is significant at the level $p<0.001{ }^{\mathrm{N} / \mathrm{S}}$ non-significant path. 


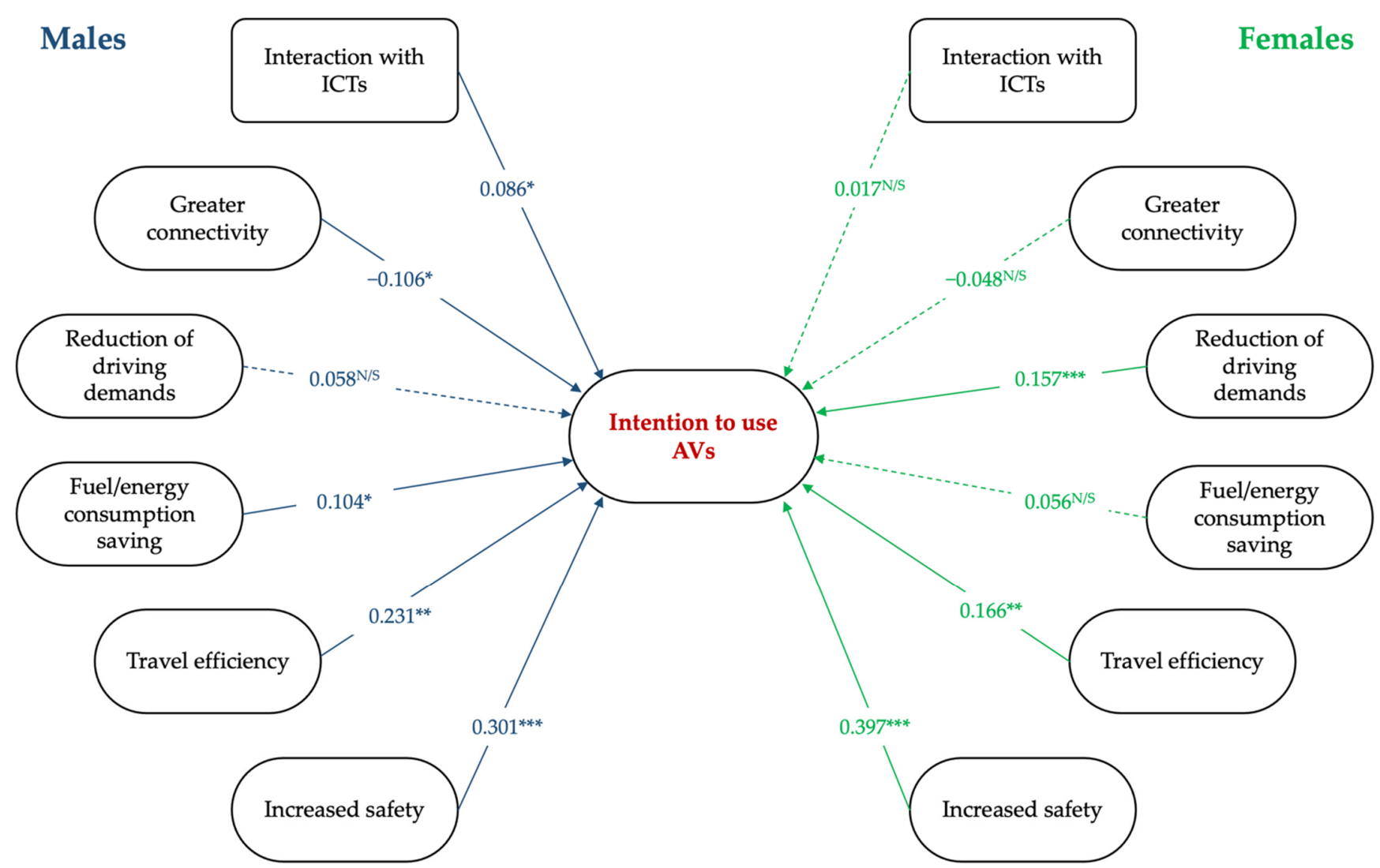

Figure 2. Multi-group structural model showing standardized path coefficients for self-reported intention to use AVs: male drivers (left) and female drivers (right). N/S Non-significant path (discontinuous arrows); ${ }^{*} p<0.050 ;{ }^{* *} p<0.010 ;{ }^{* * *} p<0.001$. Additional information on other (miscellaneous) statistical parameters is available in Table 4.

The Standardized Path Coefficients (SPCs) and their significance values (see solid lines in Figure 2 and the right column of Table 4) in the bias-corrected MGSEM suggest that there exist both structural similarities and differences, as follows:

In regard to structural similarities, the MGSEM results show only two akin path relationships between male and female drivers, namely: (i) drivers' valuation of trip efficiency, and (ii) safety improvements of automated vehicles significantly predict their intention to use them.

On the other hand, and as for structural differences, it was found that: (i) drivers' degree of interaction with Information and Communication Technologies (ITCs) are a significant predictor of intention among males, but it remains non-significant for the case of female drivers; (ii) unlike the case of females, a greater connectivity seems to significantly decrease the self-reported intention among male drivers; (iii) reduction of driving demands is a significant predictor only among female drivers, and (iv) fuel/energy consumption saving significantly increases intention to use AVs only among male drivers.

\section{Discussion}

The core aims of this study were, first, to assess the relationships among drivers' demographic factors, the valuation given to five key features of automated vehicles, and their intention to use AVs, and secondly, to test the predictive role of the valuation given to these five features on drivers' intention, focusing on gender as a key differentiating factor. Therefore, the findings in each one of these regards will be discussed below, in consideration of both the study hypotheses and the existing literature on the matter.

In regard to the first aim, it was initially hypothesized that drivers' valuations of five different features greatly known about fully-automated vehicles might be significantly 
related to their self-reported intention to switch to AVs. Based on the data provided by this relatively extensive sample of 856 drivers, this study found that, indeed, there are bivariate relationships between drivers' intentions to shift to an automated vehicle and their valuation of five of its most relevant features, within those presented prospectively by the literature $[3,5,9]$. In this regard, it is worth emphasizing that, in a period of approximately 10 years (for when it is expected to be a large enough market in European countries), some other relevant features and/or technological developments could substantially affect how automated vehicles are perceived, and how transport dynamics could be transformed as a consequence of their potential impacts in different spheres $[7,40,47]$.

Further, the descriptive results of this study suggest some interesting points worthwhile to be briefly discussed: firstly, that AV feature-related valuations may largely differ on the basis of gender (to be discussed below, when addressing the second study aim), and secondly, the existence of statistically significant differences in the self-rated interaction with ICTs by gender, in which case women present significantly higher scores than their male counterparts. As for this finding, some recent studies have found that, regardless of gender gaps in terms of accessibility in many countries, but especially in emerging economies [48], females might tend to keep a greater mean daily interaction with some "connected devices" in terms of frequency, intensity, and even as for subsequent problems derived from it $[49,50]$, even though findings remain somewhat inconsistent across different literature sources.

The second aim of this study (i.e., to test the predictive role of these five key features in a gender-based perspective) allowed to a priori hypothesize that that AV-feature valuations would have a significant (but still differential) effect over drivers' intentions to use them. Overall, the results found endorsed the hypothesis that there exist certain multi-group structural [51] differences in the explanation of the intention to use an automated vehicle based on its differential features, at least between male and female drivers.

Although this multivariate technique had not been ever applied to the study of users' preferences, attitudes and/or intentions over automated vehicles (AVs), previous researches have already analyzed the role of gender as a key potential determinant and (in other cases) mediator between, demographic/psychosocial issues and perceptual and behavioral outcomes of several groups of road users (for a summary, please see: [52-54]).

Furthermore, gender differences constitute a "traditional" but underused issue in road safety and transport planning studies. With a certain frequency, gender-focused studies are solely descriptive and ignore the covariant and "invisible" relationships and effects among multiple factors, as happens in simple mean comparisons that (although still interesting), do not properly delve into the mechanisms by which multiple gender differences can simultaneously interact $[51,53]$. Therefore, and beyond the significant mean differences found in these terms, this study provides an in-depth analysis of the differential role of various features expected to be found in SAE 5 level cars between drivers of both genders, serving as a starting point for further research on the matter.

Addressing each one of the six variables included in the significant MGSEM model as predictors of drivers' intention to use AVs, a summary is presented below:

- Interaction with ICTs. This technology demand-related variable significantly explained males' (although not females') intention in a positive way. In other words, and although the magnitude of the significant path coefficient is low, it can be assumed that male drivers keeping a greater degree of contact with technological devices might also tend to have a greater intention to shift from a conventional car to an AV. Previously, some few studies have assessed the link between interaction with ICTs and the intention of using cars provided with higher SAE level technologies, also finding a predictive (and positive) link amongst them [6,55]. Additionally, and although no gender focus had never been applied before to this specific issue, it is worth remarking how other studies have linked previous interactions between people and technology with their acceptance of new technological solutions and improvements $[56,57]$. 
- Greater connectivity of $A V s$ : Same as Interaction with Information and Communication Technologies, this feature of AVs had a structurally different role, in function to driver's gender. Namely, it negatively influenced intentions of male drivers, although not of females. In this regard, previous research endorses the role of informationrelated privacy and security as a prevalent concern for many of both technology and road users, including the case of drivers $[1,9,12,14]$. This is, in other words, an issue that (besides all current ethical discussions existing in these regards [13]) might need additional efforts aimed at (i) guaranteeing users a desirable level of security, stability and reliability [58], and (ii) communicating what are the real aspects on which the connectivity of the AVs will be used to their powerful users, in a clear, participatory and comprehensive manner [13,55,56].

- Reduction of driving demands: Contrary to what is observed in the case of the greater connectivity feature, the fact that automated cars reduce driving demands seems to represent "an incentive" (to a significant extent) only for women, among whom the predictive relationship between the feature and their intention to use AVs remains positive. In this regard, a reasonably plausible explanation is the fact that, overall, males tend to believe they perform significantly better than others in different tasks, including vehicle driving $[59,60]$, as well as being more optimistic and perceiving themselves as less prone to get in a crash, particularly when judging their own driving skills [60]. Moreover, and as vehicle automation aims at progressively decreasing the number and complexity of the demands imposed to the driver by trip-related tasks [9], and fully automated cars are designed to practically drive themselves, it is not surprising to find emerging concerns surrounding this (nowadays) set of almost unknown dynamics in transportation $[27,42]$, especially if it is taken into account that the most complex levels of automation still remain practically unexploited on public roads in the eyes of drivers $[7,16,28]$.

- Fuel/energy consumption saving: This feature, apart from depicting another structural difference in regard to AV use-related intention between male and female drivers, constituted a significant predictor only for the case of males, and the association was positive. In other words, it suggests that the extent to which an automated vehicle might be energy efficient might represent a potential issue affecting decisionmaking of male drivers, even besides what concerns environmental sustainability settings [29,32]. Consistently, few studies have argued that, apart from sustainabilityrelated factors $[30,59,61]$, fuel efficiency is a feature often pursued by drivers on the basis of an economical motivation. However, what draws more attention is the fact that it is men who, in general, show that they are more informed about fuel-efficient driving, when compared with females, as concluded by McIlroy and Stanton in a recent applied study on eco-driving knowledge performed in the United Kingdom [62].

- Travel efficiency and increased safety: In these two cases, the relationship is positive and similar in terms of magnitude. Therefore, no gender differences were found in the case of age, which showed to have a similar influence in both spheres. In other words, and coherently with previous researches performed on these two key features, this study's outcomes suggest that efficiency and safety constitute crucial issues for vehicle automation, at least in the eye of potential customers $[6,14,58]$. Therefore, the findings consistently suggest that the greater a driver's valuation of AV's trip efficiency and safety, the higher is the extent to which they are predisposed to move closer to vehicle automation for their trips [1,55], regardless of gender.

\section{Conclusions}

\subsection{Study Outcomes and Implications}

Findings from this work suggest that: firstly, drivers' demographic factors, their assessment of five features of automated vehicles (i.e., increased connectivity, reduced driving demands, fuel and trip-related efficiency, and safety improvements) keep a significant set of multivariate relationships with their intention to use them in the future. 
Secondly, and even though there are few structural similarities, the intention of drivers to use an AV can be differentially explained according to their gender, being males' intentions are affected by connectivity, fuel consumption, energy and trip efficiency, and safety-related issues, whereas females' intention to use an AV remains, rather, linked to driving demands, trip efficiency, and safety features. In brief, these differential attitudinal trends could differentiate both their preferences and potential practices related to autonomous driving in the near future.

Finally, and as for the practical implications of this study, this research constitutes the first approximation made so far to the intention of using AVs from a gender-based MGSEM approach, being these results of potential interest for many stakeholders, including:

- Firstly, researchers and practitioners on road safety can find relevant insights about (among others) the relationship between perceived safety and drivers' intention to use vehicles whose features might help decreasing their crash likelihood.

- Secondly, automotive design-related stakeholders may find it useful to find (with good empirical proof) that there are, indeed, several key differences in relation to the factors enhancing the intention to use $\mathrm{AVs}$ between male and female drivers, which can be used for product development purposes.

- Finally, one of the key issues highlighted in this study is the strategic value of automated cars for both sustainability and transport efficiency. Therefore, transport planners may find in this study a quick overview of some gender-based gaps in the valuation of e.g., energy and trip efficiency issues of $A V s$, which would be worth addressing in the near future in both planning, communication and training processes.

\subsection{Limitations of the Study and Further Research}

Although this research analyzed the data from a relatively extensive sample of drivers, which was also considerably balanced in terms of age and gender, and the essential statistical and theoretical assumptions (included Goodness-of-Fit criteria) were met, it is worth acknowledging some essential limitations and technical shortcomings that could have biased the research outcomes, so that readers will make a careful interpretation of the data presented by this study.

First of all, an anonymous interview does not fully deter common method biases (CMBs) in responses, especially if there are addressed topics related to the social discussion, such as vehicle automation and transportation dynamics. Secondly, and although based on a relatively extensive literature review, the set of AV-related features measured by this study is only partial: only a few of them, even though all which were relevant were covered

Secondly, there are many other factors potentially affecting drivers' attitudes and intentions towards AVs that remain unexplored in this research.

Thirdly, the authors consider it might be suggestible to complementarily acquire further insights on this interesting issue by means of e.g., in-depth interviews, repeated measures over time (as this is a very changing process) and mixed research methods, with the aim to maximize the explanation of gender-based differences in regard to user-related issues affecting future transportation dynamics and trends.

Author Contributions: Conceptualization, S.A.U. and M.P.-O.; methodology, S.A.U.; software, F.J.L. and M.P.-O.; validation, S.A.U., A.G.-M. and F.J.L.; formal analysis, S.A.U.; investigation, S.A.U., M.P.-O. and A.G.-M.; resources, F.J.L.; data curation, A.G.-M. and M.P.-O.; writing-original draft preparation, S.A.U. and A.G.-M.; writing-review and editing, S.A.U., M.P.-O. and A.G.-M.; visualization, F.J.L. and M.P.-O.; supervision, S.A.U. and F.J.L.; project administration, S.A.U. All authors have read and agreed to the published version of the manuscript.

Funding: This study was supported by the Spanish Foundation for Road Safety (FESVIAL) with grant RG/002/2021 (Grant recipient: S.A.U.).

Institutional Review Board Statement: The study was conducted according to the guidelines of the Declaration of Helsinki, and approved by the Ethics Committee of the Research Institute on Traffic and Road Safety at the University of Valencia (protocol code HE0002150621 from 15 June 2021). 
Informed Consent Statement: Informed consent was obtained from all subjects involved in the study.

Data Availability Statement: The data presented in this study are available upon reasonable request from the corresponding author. The data are not publicly available given that the development of other research products derived from this project is still underway.

Acknowledgments: The authors would like to thank all our partakers, research staff members, and institutional stakeholders for their active involvement in this study. A special mention to Boris Cendales for the reading proof of the final version of the manuscript.

Conflicts of Interest: The authors declare no conflict of interest regarding this manuscript.

\section{References}

1. Lijarcio, I.; Useche, S.A.; Llamazares, J.; Montoro, L. Availability, Demand, Perceived Constraints and Disuse of ADAS Technologies in Spain: Findings from a National Study. IEEE Access 2019, 7, 129862-129873. [CrossRef]

2. Roh, C.G.; Kim, J.; Im, I.J. Analysis of Impact of Rain Conditions on ADAS. Sensors 2020, 20, 6720. [CrossRef] [PubMed]

3. McKinsey \& Co. Automotive Revolution-Perspective towards 2030: How the Convergence of Disruptive Technology-Driven Trends Could Transform the Auto Industry. 2016. Available online: http:/ / go.uv.es/G6b8o63 (accessed on 10 November 2021).

4. Hryniewicz, K.; Grzegorczyk, T. How different autonomous vehicle presentation influences its acceptance: Is a communal car better than agentic one? PLoS ONE 2020, 15, e0238714. [CrossRef] [PubMed]

5. Huang, T. Research on the use intention of potential designers of unmanned cars based on technology acceptance model. PLOS ONE 2021, 16, e0256570. [CrossRef]

6. Montoro, L.; Useche, S.A.; Alonso, F.; Lijarcio, I.; Bosó-Seguí, P.; Martí-Belda, A. Perceived safety and attributed value as predictors of the intention to use autonomous vehicles: A national study with Spanish drivers. Saf. Sci. 2019, 120, 865-876. [CrossRef]

7. Malik, S.; Khan, M.A.; El-Sayed, H. Collaborative Autonomous Driving-A Survey of Solution Approaches and Future Challenges Sensors 2021, 21, 3783. [CrossRef] [PubMed]

8. Tan, H.; Zhao, F.; Hao, H.; Liu, Z. Evidence for the Crash Avoidance Effectiveness of Intelligent and Connected Vehicle Technologies. Int. J. Environ. Res. Public Health 2021, 18, 9228. [CrossRef] [PubMed]

9. Hancock, P.A.; Nourbakhsh, I.; Stewart, J. On the future of transportation in an era of automated and autonomous vehicles. Proc. Natl. Acad. Sci. USA 2019, 116, 7684-7691. [CrossRef]

10. Ghazal, T.M.; Said, R.A.; Taleb, N. Internet of vehicles and autonomous systems with AI for medical things. Soft. Comput. 2021, 1-13. [CrossRef]

11. Hancock, P.A. Driving into the Future. Front. Psychol. 2020, 11, 574097. [CrossRef]

12. Linkov, V.; Zámečník, P.; Havlíčková, D.; Pai, C.W. Human Factors in the Cybersecurity of Autonomous Vehicles: Trends in Current Research. Front. Psychol. 2019, 10, 995. [CrossRef]

13. Othman, K. Public acceptance and perception of autonomous vehicles: A comprehensive review. AI Ethics 2021, 1, 355-387. [CrossRef]

14. Lijarcio, I.; Useche, S.A.; Llamazares, J.; Montoro, L. Perceived benefits and constraints in vehicle automation: Data to assess the relationship between driver's features and their attitudes towards autonomous vehicles. Data Brief 2019, 27, 104662. [CrossRef]

15. Keszey, T. Behavioural intention to use autonomous vehicles: Systematic review and empirical extension. Transp. Res. Part C Emerg. Technol. 2020, 119, 102732. [CrossRef]

16. Liang, D.; Lau, N.; Baker, S.A.; Antin, J.F. Examining Senior Drivers' Attitudes Toward Advanced Driver Assistance Systems After Naturalistic Exposure. Innov. Aging 2020, 4, igaa017. [CrossRef]

17. Daza, I.G.; Bergasa, L.M.; Bronte, S.; Yebes, J.J.; Almazán, J.; Arroyo, R. Fusion of optimized indicators from Advanced Driver Assistance Systems (ADAS) for driver drowsiness detection. Sensors 2014, 14, 1106-1131. [CrossRef] [PubMed]

18. Useche, S.A.; Alonso, F.; Cendales, B.; Llamazares, J. More Than Just "Stressful"? Testing the Mediating Role of Fatigue on the Relationship Between Job Stress and Occupational Crashes of Long-Haul Truck Drivers. Psychol. Res. Behav. Manag. 2021, 14, 1211-1221. [CrossRef] [PubMed]

19. Serrano-Fernández, M.J.; Boada-Grau, J.; Robert-Sentís, L.; Vigil-Colet, A.; Assens-Serra, J. Predictive power of selected factors over driver stress at work. Int. J. Occup. Saf. Ergon. 2021, 27, 416-424. [CrossRef]

20. Lemke, M.K.; Apostolopoulos, Y.; Hege, A.; Sönmez, S.; Wideman, L. Understanding the role of sleep quality and sleep duration in commercial driving safety. Accid. Anal. Prev. 2016, 97, 79-86. [CrossRef]

21. Useche, S.A.; Ortiz, V.G.; Cendales, B.E. Stress-related psychosocial factors at work, fatigue, and risky driving behavior in bus rapid transport (BRT) drivers. Accid. Anal. Prev. 2017, 104, 106-114. [CrossRef] [PubMed]

22. Čulík, K.; Kalašová, A. Statistical Evaluation of BIS-11 and DAQ Tools in the Field of Traffic Psychology. Mathematics 2021, 9, 433. [CrossRef]

23. Čulík, K.; Kalašová, A.; Kubíková, S. Simulation as an Instrument for Research of Driver-vehicle Interaction. MATEC Web. Conf. 2017, 134, 8. [CrossRef]

24. De-Las-Heras, G.; Sánchez-Soriano, J.; Puertas, E. Advanced Driver Assistance Systems (ADAS) Based on Machine Learning Techniques for the Detection and Transcription of Variable Message Signs on Roads. Sensors 2021, 21, 5866. [CrossRef] 
25. Teoh, E.R.; Kidd, D.G. Rage against the machine? Google's self-driving cars versus human drivers. J. Saf. Res. 2017, 63, 57-60. [CrossRef] [PubMed]

26. Pettigrew, S.; Fritschi, L.; Norman, R. The Potential Implications of Autonomous Vehicles in and around the Workplace. Int. J. Environ. Res. Public Health 2018, 15, 1876. [CrossRef]

27. Nees, M.A. Acceptance of Self-driving Cars: An Examination of Idealized versus Realistic Portrayals with a Self- driving Car Acceptance Scale. Proc. Hum. Factors Ergon. Soc. Annu. Meet. 2016, 60, 1449-1453. [CrossRef]

28. Yuen, K.F.; Chua, G.; Wang, X.; Ma, F.; Li, K.X. Understanding Public Acceptance of Autonomous Vehicles Using the Theory of Planned Behaviour. Int. J. Environ. Res. Public Health 2020, 17, 4419. [CrossRef]

29. Brown, K.E.; Dodder, R. Energy and emissions implications of automated vehicles in the U.S. energy system. Transp. Res. D Transp. Environ. 2019, 77, 132-147. [CrossRef]

30. Massar, M.; Reza, I.; Rahman, S.M.; Abdullah, S.M.H.; Jamal, A.; Al-Ismail, F.S. Impacts of Autonomous Vehicles on Greenhouse Gas Emissions-Positive or Negative? Int. J. Environ. Res. Public Health 2021, 18, 5567. [CrossRef]

31. Freedman, I.G.; Kim, E.; Muennig, P.A. Autonomous vehicles are cost-effective when used as taxis. Injury Epidemiol. 2018, 5, 24 [CrossRef]

32. Ghadikolaei, M.A.; Wong, P.K.; Cheung, C.S.; Zhao, J.; Ning, Z.; Yung, K.F.; Wong, H.C.; Gali, N.K. Why is the world not yet ready to use alternative fuel vehicles? Heliyon 2021, 7, e07527. [CrossRef] [PubMed]

33. Backhaus, R. Battery Raw Materials-Where from and Where to? ATZelectron. Electron. Worldw. 2021, 16, 38-43. [CrossRef]

34. Weiss, M.; Zerfass, A.; Helmers, E. Fully electric and plug-in hybrid cars-An analysis of learning rates, user costs, and costs for mitigating $\mathrm{CO}_{2}$ and air pollutant emissions. J. Clean. Prod. 2019, 212, 1478-1489. [CrossRef] [PubMed]

35. Kampker, A.; Offermanns, C.; Heimes, H.; Bi, P. Meta-analysis on the Market Development of Electrified Vehicles. ATZ Worldw. 2021, 123, 58-63. [CrossRef]

36. Lajunen, T.; Sullman, M.J.M. Attitudes Toward Four Levels of Self-Driving Technology Among Elderly Drivers. Front. Psychol. 2021, 12, 682973. [CrossRef] [PubMed]

37. Mora, L.; Wu, X.; Panori, A. Mind the gap: Developments in autonomous driving research and the sustainability challenge. J. Clean. Prod. 2020, 275, 124087. [CrossRef]

38. Rousseau, S.; Deschacht, N. Public Awareness of Nature and the Environment During the COVID-19 Crisis. Environ. Resour. Econ. 2020, 76, 1149-1159. [CrossRef] [PubMed]

39. Burns, L.D.; Jordan, W.C.; Scarborough, B.A. Transforming Personal Mobility; The Earth Institute, University of Columbia: New York, NY, USA, 2013.

40. Auld, J.; Sokolov, V.; Stephens, T.S. Analysis of the effects of connected-automated vehicle technologies on travel demand. Transp. Res. Rec. 2017, 2625, 1-8. [CrossRef]

41. Childress, S.; Nichols, B.; Charlton, B.; Coe, S. Using an activity-based model to explore the potential impacts of automated vehicles. Transp. Res. Rec. 2015, 2493, 99-106. [CrossRef]

42. Sonnleitner, J.; Friedrich, M.; Richter, E. Impacts of highly automated vehicles on travel demand: Macroscopic modeling methods and some results. Transportation 2021. [CrossRef]

43. De Almeida Correia, G.H.; Looff, E.; van Cranenburgh, S.; Snelder, M.; van Arem, B. On the impact of vehicle automation on the value of travel time while performing work and leisure activities in a car: Theoretical insights and results from a stated preference survey. Transp. Res. Part A Policy Pract. 2019, 119, 359-382. [CrossRef]

44. INE. Population Figures/Basic Demographic Indicators. Web Resource; Instituto Nacional de Estadística: Madrid, Spain, 2020. Available online: https:/ / www.ine.es/dyngs /INEbase/es/operacion.htm?c=Estadistica_C\&cid=1254736176951\&menu=ultiDatos\&idp= 1254735572981 (accessed on 15 December 2021).

45. Byrne, B. Structural Equation Modeling with AMOS. Basic Concepts, Applications and Programming, 2nd ed.; Routledge Taylor \& Francis Group: New York, NY, USA, 2010.

46. Marsh, H.W.; Hau, K.T.; Wen, Z. In search of golden rules: Comment on hypothesis-testing approaches to setting cutoff values for fit indexes and dangers in overgeneralizing Hu and Bentler's (1999) findings. Struct. Equ. Model. Multidiscip. J. 2004, 11, 320-341. [CrossRef]

47. García, A.; Camacho-Torregrosa, F.J. Influence of Lane Width on Semi- Autonomous Vehicle Performance. Transp. Res. Rec. J. Transp. Res. Board 2020, 2674, 279-286. [CrossRef]

48. Garcia, D.; Mitike Kassa, Y.; Cuevas, A.; Cebrian, M.; Moro, E.; Rahwan, I.; Cuevas, R. Analyzing gender inequality through large-scale Facebook advertising data. Proc. Natl. Acad. Sci. USA 2018, 115, 6958-6963. [CrossRef]

49. Baumann, E.; Czerwinski, F.; Reifegerste, D. Gender-Specific Determinants and Patterns of Online Health Information Seeking: Results from a Representative German Health Survey. J. Med. Internet Res. 2017, 19, e92. [CrossRef]

50. Chen, B.; Liu, F.; Ding, S.; Ying, X.; Wang, L.; Wen, Y. Gender differences in factors associated with smartphone addiction: A cross-sectional study among medical college students. BMC Psychiatry 2017, 17, 341. [CrossRef]

51. Rezapour, M.; Ksaibati, K. Application of multi-group structural equation modelling for investigation of traffic barrier crash severity. Int. J. Injury Control Saf. Promot. 2020, 27, 232-242. [CrossRef]

52. Chen, H.Y.; Donmez, B. What drives technology-based distractions? A structural equation model on social-psychological factors of technology-based driver distraction engagement. Accid. Anal. Prev. 2016, 91, 166-174. [CrossRef] 
53. Useche, S.A.; Hezaveh, A.M.; Llamazares, F.J.; Cherry, C. Not gendered ... but different from each other? A structural equation model for explaining risky road behaviors of female and male pedestrians. Accid. Anal. Prev. 2021, 150, 105942. [CrossRef]

54. Useche, S.A.; Montoro, L.; Alonso, F.; Tortosa, F.M. Does gender really matter? A structural equation model to explain risky and positive cycling behaviors. Accid. Anal. Prev. 2018, 118, 86-95. [CrossRef]

55. Nordhoff, S.; Stapel, J.; van Arem, B.; Happee, R. Passenger opinions of the perceived safety and interaction with automated shuttles: A test ride study with 'hidden' safety steward. Transp. Res. Part A Policy Pract. 2020, 138, 508-524. [CrossRef]

56. Habibovic, A.; Lundgren, V.M.; Andersson, J.; Klingegård, M.; Lagström, T.; Sirkka, A.; Fagerlönn, J.; Edgren, C.; Fredriksson, R.; Krupenia, S.; et al. Communicating Intent of Automated Vehicles to Pedestrians. Front. Psychol. 2018, $9,1336$. [CrossRef] [PubMed]

57. Woods, D.D. Commentary designs are hypotheses about how artifacts shape cognition and collaboration. Ergonomics 1998, 41, 168-173. [CrossRef]

58. Ahangar, M.N.; Ahmed, Q.Z.; Khan, F.A.; Hafeez, M. A Survey of Autonomous Vehicles: Enabling Communication Technologies and Challenges. Sensors 2021, 21, 706. [CrossRef]

59. Al-Balbissi, A.H. Role of Gender in Road Accidents. Traffic Inj. Prev. 2003, 4, 64-73. [CrossRef]

60. Ring, P.; Neyse, L.; David-Barett, T.; Schmidt, U. Gender Differences in Performance Predictions: Evidence from the Cognitive Reflection Test. Front. Psychol. 2016, 7, 1680. [CrossRef] [PubMed]

61. Muro-Rodríguez, A.I.; Perez-Jiménez, I.R.; Gutiérrez-Broncano, S. Consumer Behavior in the Choice of Mode of Transport: A Case Study in the Toledo-Madrid Corridor. Front. Psychol. 2017, 8, 1011. [CrossRef]

62. McIlroy, R.C.; Stanton, N.A. What do people know about eco-driving? Ergonomics 2017, 60, 754-769. [CrossRef] 